\title{
Health Technology Assessment as a Priority-Setting Tool for Universal Health Coverage: The Call for Global Action at the Prince Mahidol Award Conference 2016
}

\author{
Yot Teerawattananon ${ }^{1} \cdot$ Alia Luz $^{2}$
}

Published online: 11 December 2015

(c) Springer International Publishing Switzerland 2015

Imagine you are a decision maker in a country that has committed to universal health coverage (UHC). Your government will provide health services to your constituents according to their needs but regardless of their ability to pay. You are part of the committee deciding what services should be provided to whom and at what costthis is called the Health Benefits Package. Since your country, similar to all others, has limited health resources and cannot offer every service available, especially highcost ones, it is necessary for you to set priorities within and across health problems and for different groups of populations, which is a difficult task.

This situation happens to decision makers in many countries, given that 75 countries have now legislated UHC [1]. Surprisingly, there is relatively little guidance and experience sharing in the existing literature on health benefits package development (i.e. searching from PubMed using the keywords "health benefits package" and "health basket" yielded only 16 and 17 hits, respectively). Moreover, decision makers' work nowadays is likely to be more difficult than it was 50 years ago, when only one or a few treatment choices were available for each disease and at relatively low cost. For example, only one option was available for adjuvant therapy for stage III colon cancer in 1989 [2], but there

Alia Luz

alialuz90@gmail.com; alia.1@hitap.net

$1 \quad$ Health Intervention and Technology Assessment Program (HITAP), 6th Floor, 6th Building, Department of Health, Ministry of Public Health (MOPH), Nonthaburi 11000, Thailand

2 HITAP International Unit (HIU), 6th Floor, 6th Building, Department of Health, Ministry of Public Health (MOPH), Mueang, Nonthaburi 11000, Thailand are now nine choices in the recent evaluation, of which the most expensive treatment regimen has a medicine price that is 32 times higher than the least expensive alternative [3].

Decisions for healthcare become more complex with UHC. In the past, doctors advised patients based on clinical benefit, while patients chose their treatment options based on ability to pay. In this situation, doctors recognise patients' limitations in selecting treatments. However, with UHC, the doctor and patient are no longer responsible for directly paying for treatments - there is now a third party, the government, which manages decisions on a higher level for the whole healthcare system. The doctor and the patient disregard the cost limitations and often require the best treatment, thus together putting pressure on those making decisions. Doctor-patient collaboration sparks media interest, and is also supported by industry, another player, which aim to have their products included in the benefits package in order to guarantee procurement in large quantities.

As such, the government requires a robust process and evidence in order to ensure that the health benefits package decisions are systematic, transparent and acceptable to all stakeholders. Experience from countries such as Australia, Canada, Thailand and the UK indicates that health technology assessment (HTA), a "multidisciplinary policy research, in generating evidence to inform prioritization, selection, introduction, distribution, and management of interventions for health promotion, disease prevention, diagnosis and treatment, and rehabilitation and palliation", can be helpful in supporting this purpose [4-7]. In Thailand and the UK, in particular, decision makers not only successfully include interventions in their benefits packages but are also able to decline including unnecessarily costly or unproven interventions as well as set standards for other countries in the regions. 
In May 2014, all Member States of the World Health Organization (WHO) endorsed the World Health Assembly (WHA) Resolution on Health Intervention and Technology Assessment (HITA) in support of UHC [8]. In this resolution, the Member States requested the WHO to review the current situation and support strengthening HTA capacity in countries as well as integrate HTA concepts and principles into the relevant strategies and areas of work of the WHO. The resolution also urged country decision makers and stakeholders to develop and use HTA capacity in supporting evidence-informed decision making.

In recent years, global communities witnessed a significant improvement in this area through the establishment of many regional initiatives and networks on HTA, such as HTAsiaLink (http://www.htasialink.org/), RedETSA (http://redetsa.org/) and the HTA regional network in the Eastern Mediterranean and North Africa (http://ezcollab. who.int/?p5y4ltajzknxzh7). In addition, annual and bi-annual conferences organised by the likes of Health Technology Assessment International (HTAi) and the International Society for Pharmacoeconomics and Outcomes Research (ISPOR) are becoming more and more prominent, with participants from many emerging economy countries attending. The International Network of Agencies for Health Technology Assessment (INAHTA), which is an international network of HTA public agencies, now has 55 member agencies from 33 countries, including 13 from low- and middle-income countries (http://www. inahta.org/). The National Institute for Care and Excellence (NICE) and the Health Intervention and Technology Assessment Program (HITAP) established international arms to provide technical support globally through the international Decision Support Initiative (iDSI).

Despite these improvements, there is still limited supply to meet the growing demand for HTA. The International Organizing Committee (IOC) of the Prince Mahidol Award Conference (PMAC), which includes the Bill and Melinda Gates Foundation, the China Medical Board (CMB), The Global Fund, the Japan International Cooperation Agency (JICA), the Rockefeller Foundation, the World Bank (WB), the WHO, the United States Agency for International Development (USAID) and the Thai government, decided to have its conference in 2016 focus on the issue of priority setting for UHC. Aiming to attract around 600-800 delegates, this conference is by invitation only, including policymakers, senior officers and staff of national bodies that are responsible for the resource allocation decisions in UHC, including the Ministry of Finance, Ministry of Health and other relevant agencies, HTA agencies, civil society organisations, international organisations and development partners, academic institutes and industry.

This conference aims to disseminate priority-setting practices globally. The Bangkok statement was developed through a consultation with the co-hosts to provide guidance and garner support and commitment from countries, national governments, development partners and other healthcare stakeholders to develop fair, transparent, systematic and evidence-based priority-setting processes that will support UHC goals. The Bangkok statement will be discussed in depth during PMAC 2016, which will be held on 26-31 January 2016 in Bangkok, Thailand, and is now available for public comments. The introduction of the WHA Resolution on HITA, due to be reported back in May 2016, will incorporate these discussions as well.

Decision makers and stakeholders and the PMAC share the same goals - the PMAC creates a learning environment in which decision makers and stakeholders can come together and find ways to improve their own healthcare systems, and they in turn can inform necessary actions towards this end during the conference, consequently forming future healthcare initiatives and focus. Thus, readers are strongly encouraged to visit the conference website (http://www.pmaconference.mahidol.ac.th/index. php?option=com_content $\&$ view=article $\&$ id=758\&Itemid) and comment on the Bangkok statement to ensure healthcare is provided for all people through a justified resource allocation process.

Acknowledgments The Health Intervention and Technology Assessment Program (HITAP) works as a technical lead for the planning of the Prince Mahidol Award Conference (PMAC). However, the authors did not have financial support for the writing of this editorial. HITAP's International Unit was established with support from the Thai Health-Global Link Initiative Project (TGLIP), the international Decision Support Initiative (iDSI) funded by the Bill and Melinda Gates Foundation and the Department of International Development, UK, and the Rockefeller Foundation to provide technical assistance on health intervention and technology assessment for governments of low- and middle-income countries.

The content of this article does not necessarily reflect the views of the aforementioned agencies.

\section{References}

1. Stuckler D, Feigl AB, Basu S, McKee M. The political economy of universal health coverage. Background paper for the global symposium on health systems research. Geneva: WHO; 2010.

2. Brown ML, Nayfield SG, Shibley LM. Adjuvant therapy for stage III colon cancer: economics returns to research and cost-effectiveness of treatment. J Natl Cancer Inst. 1994;86(6):424-30.

3. Lerdkiattikorn P, Chaikledkaew U, Lausoontornsiri W, Chindavijak S, Khuhaprema T, Tantai N, et al. Cost-utility analysis of adjuvant chemotherapy in patients with stage III colon cancer in Thailand. Expert Rev Pharmacoecon Outcomes Res. 2015;15(4):687-700. doi:10.1586/14737167.2015.972379.

4. Clement FM, Harris A, Li JJ, Yong K, Lee KM, Manns BJ. Using effectiveness and cost-effectiveness to make drug coverage decisions: a comparison of Britain, Australia, and Canada. JAMA. 2009;302(13):1437-43. doi:10.1001/jama.2009.1409.

5. Guthrie S, Bienkowska-Gibbs T, Manville C, Pollitt A, Kirtley A, Wooding S. The impact of the National Institute for Health 
Research Health Technology Assessment programme, 2003-13: a multimethod evaluation. Health Technol Assess. 2015;19(67):1-292. doi:10.3310/hta19670.

6. Mohara A, Youngkong S, Velasco RP, Werayingyong P, Pachanee $\mathrm{K}$, Prakongsai $\mathrm{P}$, et al. Using health technology assessment for informing coverage decisions in Thailand. J Comp Eff Res. 2012;1(2):137-46. doi:10.2217/cer.12.10.
7. Turner S, Bhurke S, Cook A. Impact of NIHR HTA Programme funded research on NICE clinical guidelines: a retrospective cohort. Health Res Policy Syst. 2015;13:37. doi:10.1186/s12961015-0025-8.

8. WHO. Health technology assessment. 2015. http://www.who.int/ medical_devices/assessment/en/. Accessed 19 Oct 2015. 